\title{
Demokratie im Präsens. Eine Theorie der politischen Gegenwart
}

Isabell Lorey

Frankfurt am Main 2020: Suhrkamp, 217 S.

\section{Gundula Ludwig}

Institut für Interkulturelle und Internationale Studien, Universität Bremen

E-Mail: gundula.ludwig@uni-bremen.de
Das Buch ist eine politisch-theoretische Intervention in aktuelle Debatten zur Krise der Demokratie und ein radikaler Neu-Entwurf von Demokratie. Die gegenwärtige Krise, die sich u.a. in Austeritätspolitik und Autoritarisierung von Politik seit der Finanz- und Schuldenkrise 2008 und im Aufstieg des Rechtspopulismus zeigt, begreift Lorey als Zuspitzung der Aporien liberaler, repräsentativer Demokratie. Diese sei „in ihren grundlegenden Institutionen paradoxerweise zutiefst undemokratisch“ (8), sie könne den Anspruch auf Gleichheit nicht einlösen, konzipiere den Demos als identitäre Einheit statt als heterogene Vielheit und begrenze das Politische, indem sie dieses vom Sozialen und Privaten trenne und zudem nationalstaatlich einhege.

Das Innovative an Loreys Zeitdiagnose zur krisenhaften Demokratie liegt darin, dass sie neue Verbindungslinien zieht, indem sie diese mit Zeit, Geschichte und Schulden zusammenbringt. Die liberale, repräsentative Demokratie basiere auf einer Fortschrittslogik, sie werde als „Geschichte der Sieger" (I6) erzählt. Soziale Bewegungen und Kämpfe seien dann erfolgreich, so das Meta-Narrativ liberaler Demokratien, wenn sie in einer Gründung einer Partei oder ähnlichen politischen Organisationen münden. Zudem bediene die liberale Demokratie eine "Geschichtsblindheit" (I6) und eine „authentizistische Unmittelbarkeit“ (I7). In der argumentativen Verbindung von Demokratie und Schuldenökonomie baut Lorey auf ihren vorangegangenen Arbeiten auf, in denen sie Prekarisierung als eine Regierungstechnik im Foucaultschen Sinne konzeptualisierte. Dieses Argument erweitert Lorey nun und zeigt, dass auch Schulden Regierungstechniken sind. Im Lichte der Corona-Krise erlangt Loreys Ausgangsthese, dass „es kein Jenseits der
Verschuldung gibt“ (I74), da es in der Schuldenökonomie nicht nur um individuelle Schulden, sondern auch um Staatsschulden gehe, brisante Aktualität. Als Regierungstechnik gehe die Schuldenökonomie mit einer spezifischen Form der Subjektivierung einher: „die doppelt verschuldete und selbstverantwortliche Persönlichkeit, die in sich selbst investiert und mit sich spekuliert" (I73I74). Durch diese Subjektivierung werde die grundlegende Unberechenbarkeit des Lebens, der Gesellschaft, der Zukunft berechenbar gemacht. Der Kredit beute „die sozialen Beziehungen und Lebensweisen“ (I77) aus und sei „asozial und ohne Interesse an der Sorge“ (I84). Hier macht Lorey die der Schuldenökonomie inhärente maskulinistische, weiße Logik sichtbar: Denn diese beruhe auf dem Phantasma der Freiheit und gebe vor, dass Abhängigkeit und Verschuldung überwindbar seien. Die Verwobenheit von Kapitalismus und Sklaverei führe zudem dazu, dass bis in die Gegenwart Schwarze und People of Color in der Schuldenökonomie zu „NochNicht-Weiß(en)“ (I82) gemacht werden und zugleich das weiße Überlegenheitsnarrativ bestätigt wird. „Der weiße Schuld/endiskurs verlangt von seinen Anderen eine doppelte Unterwerfung: Selbstdisziplin als Be/Frei/t/e und die Affirmation der ewigen Schuld als Unterordnung unter weiße Überlegenheit. Getrieben von dem Versprechen und dem Begehren zukünftiger Ungebundenheit." (I84) Die Krise der Demokratie ist folglich nicht nur eine Krise der Institutionen der Demokratie, sondern geht einher mit maskulinistischen, weißen Regierungstechniken der Prekarisierung und Schuldenökonomie.

Gegen eine derartige Gegenwart setzt Lorey die präsentische Demokratie, die sie in den Platzbesetzungen in Madrid, Athen, Kairo und Istanbul, vor allem aber in 
queer-feministischen transnationalen Streiks zum 8. März und den Kämpfen „NI UNA MÁS“ als gelebte Praxen sieht. Um den Einsatz der Demokratie im Präsens ausführen zu können, bringt Lorey das Wissen um Politik, das in sozialen Bewegungen generiert wird, in einen Dialog mit Politischer Theorie. Jeweils ein Kapitel ist einer Relektüre eines politischen Theoretikers gewidmet: Jean-Jacques Rousseaus Augenmerk auf den Austausch der zusammenkommenden Multitude, die jedoch durch das maskulinistische Volk verengt und in der Politischen Ideengeschichte verdrängt wird; Jacques Derridas nichtidentitäre Perspektive auf Demokratie im Werden; Walter Benjamins Geschichtsverständnis, das an die Stelle der ,Geschichte der Sieger' die Verwobenheit von Geschichte und Gegenwart setzt, die in Kämpfen aktualisiert wird; Michel Foucaults ,infinitive Gegenwart'; und Antonio Negris Konzeptualisierung der konstituierenden Macht der Multitude als Suspendierung der liberalen Trennung von Sozialem und Politischem.

Derart ausgestattet mit theoretischem und aktivistischem Wissen akzentuiert Lorey im letzten Kapitel die Demokratie im Präsens als eine, die Zeit- und Geschichtslogik und die Schuldenökonomie der liberalen Demokratie überkommt: An die Stelle des Fortschrittsphantasmas und des Fokus auf Institutionalisierung stellt Lorey die vielfältigen Praxen, in denen Demokratie bereits erprobt wird; statt Geschichtsvergessenheit zielt die präsentische Demokratie darauf ab, „minoritäre Geschichtsfragmente" dem Vergessen zu entreißen und zu „aktualisieren“ (I7). Die Logik der linearen Zeitlichkeit wird durchkreuzt, indem - hier bedient sich Lorey Benjamins Figur des Tigersprungs - vergangene Kämpfe aktualisiert werden. Zentral für die präsentische Demokratie sind neue Formen der Subjektivierung, Sorge und gegenseitige Verschuldung. Nicht abgeschlossene Identitäten, sondern „nicht-identitäre Verbundenheiten und Affizierungen“"(19) sind Grundlage. An die Stelle der moralischen, weißen, maskulinistischen Schulden tritt eine ethische Perspektive auf Schulden jenseits des Freiheitsphantasmas. Die Fortschrittslogik, die die liberale Demokratie wie die Schuldenökonomie gleichermaßen antreiben, wird durchbrochen: Statt sich von Zukunftsversprechen regieren zu lassen, wird Demokratie im Präsens gelebt.

Die Krise der Demokratie stellt seit vielen Jahren eines der Kernthemen der Politikwissenschaft dar. Loreys Buch ist für Debatten dazu gewinnbringend, da es die üblichen Denkpfade verlässt. Durch die Verbindung von Demokratie mit Zeitlichkeit, Subjektivierung und Schulden stellt das Buch für Gegenwartsdiagnosen zur Malaise der Demokratie wie für einen Entwurf einer demokratischen Demokratie gewichtige Argumente bereit. Zudem zeigt Lorey, wie sehr Politische Theorie durch Wissensproduktionen an der Schnittstelle von Theorie und Aktivismus und dem Überkommen des weißen, maskulinistischen Kanons profitiert. Loreys Auseinandersetzung mit sozialen Bewegungen der Sorge, des Lebens und Alltags als Demokratiebewegungen sowie eine queer-feministische, eurozentrismuskritische Perspektivierung des Politischen führt in der Tat $\mathrm{zu}$ einem radikalen Neudenken von Demokratie, von deren Dringlichkeit die Gegenwart eigentlich kontinuierlich Zeugnis ablegt. 